\title{
O PIBID COMO POSSIBILIDADE DE INSERÇÃO DE PROFESSORES EM FORMAÇÃO EM PRÁTICAS DE LETRAMENTO ACADÊMICO
}

\section{THE PIBID PROGRAM AS A POSSIBILITY OF INSERTION IN LITERACY ACADEMIC PRACTICES FOR TEACHERS IN TRAINING}

\author{
FRITZEN, Maristela Pereira \\ mpfritzen@gmail.com \\ FURB - Universidade Regional de Blumenau \\ FISCHER, Adriana \\ afischerpirotta@gmail.com \\ FURB - Universidade Regional de Blumenau
}

\begin{abstract}
RESUMO O objetivo do presente artigo é discutir a inserção de estudantes do curso de Letras em práticas de letramento acadêmico, por meio de leituras e produções escritas no âmbito do Programa Institucional de Bolsas de Iniciação à Docência (PIBID), a partir de sua participação no Subprojeto de Letras-Português da Universidade Regional de Blumenau (FURB). A concepção teórico-metodológica tem por base os estudos dos letramentos acadêmicos, com ênfase em práticas socioculturais situadas, das quais se analisam relatórios mensais e diários de campo elaborados pelas acadêmicas ao longo de dois anos de inserção no PIBID. Os dados se organizam em torno de quatro dimensões: (i) práticas leitoras de conteúdo científico e pedagógico; (ii) escolhas pedagógicas; (iii) práticas de escrita e oralidade de gêneros discursivos da esfera acadêmica; (iv) interação com outros acadêmicos em eventos científicos. Os resultados da análise da inserção das licenciandas/pibidianas em práticas de letramento acadêmico sinalizam como elas vão constituindo sua nova identidade - a docente, ao lado da identidade de membros efetivos em Discursos acadêmicos. Essas diferentes formas de inserção em práticas sociais de letramento acadêmico marcam fronteiras entre 0 ser estudante, no ensino superior, e o ser professor na educação básica.
\end{abstract}

PALAVRAS-CHAVE: PIBID. Língua portuguesa. Letramentos acadêmicos.

ABSTRACT The purpose of this article is to discuss the insertion of Language Teaching undergraduate students in academic literacy practices through reading and written production in the Brazilian Institutional Scholarship Program for Teaching Introduction (Programa Institucional de Bolsas de Iniciação à Docência - PIBID), by their participation in the Subproject of Portuguese Language at Universidade Regional de Blumenau (FURB). The theoretical and methodological approach is based on academic literacy studies, with emphasis on situated sociocultural practices, in which monthly and daily field reports prepared by the academic have been analyzed over two years of their participation in the PIBID Program. Data are organized around four dimensions: (i) reading practices of scientific and educational content; (ii) pedagogical choices; (iii) writing and oral practices of discursive genres in the academic sphere;(iv) interaction with other undergraduate students in scientific 
events. The analysis results of PIBID undergraduate teaching students' integration in academic literacy practices indicate how they constitute their new teaching identity, along with their identity as members of academic discourses. Those different forms of insertion in social practices of academic literacy set boundaries between the higher education student being, and the primary education teacher being.

KEYWORDS: PIBID. Portuguese. Academic literacies.

\section{INTRODUÇÃO}

A formação inicial e continuada de professores tem sido foco recorrente de férteis debates, especialmente se considerados os desafios atuais para se melhorar de forma efetiva a educação básica. No centro das discussões situam-se temáticas relativas ao desempenho dos alunos/as do ensino fundamental e médio de escolas públicas frente às avaliações em larga escala, nacionais e internacionais, à necessidade de valorização do magistério como campo profissional e à emergência do aprimoramento da formação docente diante da complexidade das sociedades contemporâneas, marcadas por constantes transições, seja no nível social, cultural, tecnológico, entre outros.

O Programa Institucional de Bolsa de Iniciação à Docência (PIBID), criado no contexto da Política Nacional de Formação de Profissionais do Magistério da Educação Básica, por meio do Decreto 6755/2009, surgiu como um dos desdobramentos e uma possível resposta a esse debate. O Programa busca elevar o padrão de qualidade da educação básica por meio do incentivo à formação inicial de acadêmicos de licenciatura de instituições de ensino superior públicas (federais, estaduais e municipais) ou comunitárias sem fins lucrativos.

Considerando o espaço de discussão deste artigo, nossa experiência como coordenadoras do PIBID e nossas pesquisas envolvendo os estudos dos letramentos, pretendemos focar nossa reflexão em um dos fatores relacionados à melhoria da formação dos professores. Entre os objetivos do Programa, está a contribuição "para a articulação entre teoria e prática necessárias à formação dos docentes, elevando a qualidade das ações acadêmicas nos cursos de licenciatura" (CAPES, 2014). A efetivação desse objetivo passa necessariamente pela ampliação aos licenciandos das condições de circulação social e inserção em práticas de 
letramentos, envolvendo os letramentos acadêmicos e os multiletramentos (FISCHER, 2007; 2011; THE NEW LONDON GROUP, 2000).

Com essa perspectiva em vista, objetivamos neste artigo discutir a inserção de acadêmicas do curso de Letras em práticas sociais de letramento acadêmico, por meio de leituras e produções escritas no âmbito do PIBID, a partir de sua participação no Subprojeto de Letras-Português da FURB (Universidade Regional de Blumenau).

Os dados indicam que, ao interagirem com leituras tanto de conteúdo pedagógico como leituras teóricas do campo da linguagem, ao produzirem gêneros acadêmicos, ao se tornarem autoras por meio de publicações diversas, ao socializarem suas experiências em eventos, as licenciandas estão num processo contínuo de construção de sentidos situados nas práticas. Essa diversidade de práticas de leitura e de escrita oportunizadas pelo PIBID se inter-relaciona e vai constituindo a trajetória de letramento dessas futuras professoras.

O texto estrutura-se em três tópicos, seguidos das considerações finais/implicações. Iniciamos discorrendo sobre as concepções de letramentos e letramentos acadêmicos. Na sequência, apresentamos o PIBID e o Subprojeto de Letras, bem como explicitamos como foram gerados os registros utilizados para análise neste artigo. Em seguida, analisamos os dados, com vistas a articular as experiências das licenciandas na formação inicial com o PIBID à sua inserção em práticas de letramento acadêmico.

\section{LETRAMENTOS: ENFOQUES TEÓRICOS À COMPREENSÃO DAS PRÁTICAS NO PIBID}

O fenômeno do letramento (cf. FISCHER, 2007) é compreendido, neste estudo, a partir de uma perspectiva sociocultural, com apoio dos Novos Estudos do Letramento (GEE, 1999; STREET, 2003; BARTON; HAMILTON, 2000). Conforme Gee (1999, p.122), caracterizar qualquer segmento como "novo" pode ser um problema. No entanto, o que justifica a caracterização "novos" a esses estudos é a condição de que leitura, escrita e sentido são sempre situados em práticas sociais específicas. Acrescentam Lankshear, Gee e Knobel (2002, p. 3, tradução nossa) que esses "estudos do letramento privilegiam o sentido a habilidades mecânicas, o qual 
é compreendido muito mais em termos de processos socioculturais que estados ou eventos cognitivos internos." Street (2003), já na década de 1980, afirma que a posição dos Novos Estudos do Letramento ressalta o letramento como prática de cunho social e não meramente uma habilidade técnica, neutra, imutável e/ou universal situada no interior dos indivíduos.

Nas palavras de Dionísio (2006), esta forma particular de entender a natureza das práticas de usos dos textos, bem como a questão da construção de sentidos, conduz à adoção de uma perspectiva de letramento como:

Conjunto flexível de práticas culturais definidas e redefinidas por instituições sociais, classes e interesses públicos em que jogam papel determinante as relações de poder e de identidades construídas por práticas discursivas que posicionam os sujeitos por relação à forma de aceder, tratar e usar os textos e os artefactos e tecnologias que os veiculam (DIONÍSIO, 2006, p.26).

Esta abordagem dá ênfase a um conjunto plural de práticas sociais, que permite o uso de diferentes formas de linguagem em uma mesma ou diversificada(s) cultura(s) e que autoriza, também, a conceituação do letramento em sua versão plural - letramentos. Diante dessa breve caracterização da perspectiva, que embasa os estudos realizados neste trabalho, ficam explícitas as influências socioculturais sobre o fenômeno do letramento.

Um conceito chave que auxilia na compreensão desse fenômeno são os eventos de letramento, que é mais bem compreendido em paralelo a outro: as práticas de letramento.

As práticas de letramento representam "os modos culturais em geral de utilização da linguagem escrita pelas quais as pessoas fazem uso em suas vidas" (BARTON; HAMILTON, 2000, p. 7, tradução nossa). No entanto, as práticas de letramento não são unidades observáveis de comportamento, já que envolvem valores, atitudes, sentimentos e relações sociais. Incluem o julgamento das pessoas sobre letramento, construções e discursos do letramento, como falam sobre e como constroem sentidos com e para o letramento. As práticas de letramento, conforme esses autores, são mais bem compreendidas na existência de relações entre pessoas, entre grupos e comunidades, não se fechando a um conjunto de propriedades unicamente internas dos indivíduos. 
Se as práticas, no sentido de maneiras culturais de utilização do letramento, são unidades que não podem ser observadas, na sua totalidade, em pequenas atividades e tarefas, os eventos de letramento representam episódios observáveis, os quais se formam e se constituem através dessas práticas. Eventos são atividades onde o letramento tem uma função, são ocasiões em que os textos fazem parte da natureza das interações dos participantes e de seus processos interpretativos (HEATH, 1983). Decisivo, segundo Street (2003), é compreender e relacionar convenções e suposições subjacentes aos eventos que fazem com que eles funcionem.

Os textos, como os relatórios e diários, partem dos eventos e práticas de letramento, os quais são foco de análises neste artigo, situam-se em contextos mais amplos e fazem emergir os eventos de letramento por terem uma motivação de uso (inserção, participação num grupo social, notabilidade, informação, estudo etc.). Os sentidos dos textos, por sua vez, são socialmente situados, contextualizados, não têm valor de ser na independência dos sentidos sociais. Em resumo, "as práticas de letramento têm finalidades e estão inseridas em objetivos sociais e práticas culturais mais vastas" (BARTON; HAMILTON, 2000, p. 12, tradução nossa).

Como, neste estudo, o contexto acadêmico em que ocorre o PIBID é o centro das atenções, enfocamos os letramentos acadêmicos (FISCHER, 2011; STREET, 2003). Apesar de a denominação letramentos acadêmicos ser perfeitamente plausível a outros contextos, que envolvam ambientes e práticas formais de escolarização (a exemplos do ensino fundamental e do ensino médio), quer-se ressaltar particularidades da esfera acadêmica no âmbito das práticas do PIBID. As particularidades, dentre várias que poderiam ser elencadas, dizem respeito, neste trabalho, ao uso das linguagens - especializadas, contextualizadas no contexto acadêmico. Ainda, fazem referência aos papéis sociais de alunos e professores, às finalidades de os alunos estarem neste domínio, e às relações estabelecidas com o conhecimento e com o saber. Todos esses aspectos inevitavelmente inter-relacionam-se, pois o letramento, compreendido como práticas sociais, envolve Discursos, com D maiúsculo, (cf. GEE, 1999; 2001), os quais se constituem por formas de ser, falar, ouvir, escrever, ler, agir, interagir, acreditar, 
valorizar, sentir, usar recursos, ferramentas, tecnologias capazes de ativar identidades relevantes num dado contexto.

Para melhor situar os letramentos acadêmicos, adotamos o modelo dos letramentos acadêmicos, segundo Lea e Street (2006), que compreende as práticas letradas em contexto acadêmico para além de um conjunto de habilidades de leitura e escrita que os estudantes necessitam operacionalizar. $O$ destaque é para os sentidos, as identidades em construção e as relações de poder e autoridade que constituem essas práticas sociais de uso da linguagem.

Nas interações, nessas práticas no contexto acadêmico, os estudantes se deparam com gêneros discursivos (BAKHTIN, 1997) próprios desse ambiente educacional, como resumos para congressos, artigos científicos, relatórios, e distintos dos estudados nos anos anteriores de escolarização, pois passam a participar de novas práticas acadêmicas de letramento em que tais gêneros circulam. Nos cursos de formação de professores, como o de Letras, onde ocorre o PIBID, por exemplo, há letramentos que vão além dos conhecimentos especializados, próprios de cada disciplina, chegando às práticas pedagógicas, na relação com ações voltadas para o ensino. Esse argumento nos auxilia a analisar, além de outras dimensões, as escolhas pedagógicas que se manifestam nos relatórios e diários das acadêmicas do PIBID Letras. Com base na leitura e na produção textual relativamente ao contexto educacional, o estudante precisa desenvolver conhecimentos, atitudes e valores sobre gêneros discursivos de tal contexto e agir por meio deles, constituindo seus letramentos acadêmicos em práticas próprias do curso em que está inserido. Nas relações dos sujeitos com a linguagem, é que vai se revelando a constituição letrada dos estudantes na condição de professores, a qual é socialmente situada (GEE, 1999) e é construída gradativamente.

Consideramos, assim, que os textos, exemplares de diferentes gêneros discursivos, fazem emergir as relações de poder em práticas sociais, pois há determinações sobre objetos de trabalho na Universidade, linguagem especializada e conteúdos específicos de acordo com as propostas no curso. Dessa forma, defendemos ser fundamental acompanhar o que as pessoas precisam saber em 
determinado contexto para serem consideradas letradas, uma vez que elas vão se constituindo segundo usos da linguagem.

\section{O PIBID E O SUBPROJETO DE LETRAS PORTUGUÊS}

A FURB passou a integrar o Programa no ano de 2010, por meio do Edital $\mathrm{n}^{\circ}$. 018/2010/CAPES - PIBID Municipais e Comunitárias. Inicialmente foram contemplados Subprojetos dos cursos de Matemática, Música, Ciências Sociais, Pedagogia e Química. Em 2011, por meio do edital, 001/2011, foram contemplados os cursos de licenciatura em Letras (15 bolsistas, três supervisores e três escolas), Educação Física (20 bolsas, quatro supervisores e quatro escolas) e Matemática (20 bolsas, dois supervisores e duas escolas). A partir de então, a FURB tem mantido o Programa no âmbito da instituição. Atualmente, há onze Subprojetos em desenvolvimento, envolvendo as licenciaturas de Pedagogia, Letras Português/Inglês e Letras Alemão (Subprojeto Letras-Português, Letras-Alemão, Letras-Inglês), Matemática, História, Ciências Sociais, Educação Física, Ciências Biológicas e Música, além de um subprojeto interdisciplinar.

O curso de Letras da FURB passou, assim, a fazer parte do Programa em 2011, com o Subprojeto Letras, voltado ao ensino da língua portuguesa. Nesse primeiro Subprojeto, o foco esteve na produção de narrativas escritas por parte de alunos do ensino fundamental. Os licenciandos participaram de formações teóricas referentes aos princípios de organização do sistema de escrita, no nível da palavra e do texto, e do esquema das narrativas (SCLIAR-CABRAL; GRIMM-CABRAL, 1984). Fizeram observação do espaço escolar, das aulas, e um diagnóstico da escrita dos alunos nesse segmento de ensino. A partir dos estudos teóricos e desse diagnóstico, foram planejadas e desenvolvidas, com a supervisora ${ }^{1}$ nas escolas, um conjunto de ações pedagógicas relativas ao trabalho com a escrita, que pudesse ampliar e qualificar os conhecimentos textuais desses alunos, especialmente na escrita de narrativas. Essa primeira experiência do PIBID, em termos de produção

\footnotetext{
${ }^{1}$ Supervisora é a professora da educação básica, nesse caso, de Língua Portuguesa, que participa do Subprojeto, como coformadora dos licenciandos. Assim como os acadêmicos, chamados de bolsistas de iniciação à docência (bolsistas ID) e o coordenador do Subprojeto na Universidade, o supervisor também recebe bolsa do PIBID.
} 
acadêmica dos licenciandos, possibilitou a participação dos bolsistas em importantes eventos regionais e nacionais, gerou resumos e trabalhos publicados em Anais de congressos, bem como artigos científicos publicados em revistas Qualis/Capes e livros (vide, entre eles, HUBER et al., 2013; KLOTH; SCHLICHTING, 2014).

Após essa primeira experiência do Subprojeto, com base nos resultados alcançados e nas demandas da educação básica, foi criado um novo Subprojeto, com foco em projetos de letramentos. Com base em Kleiman (2000, p. 238, grifos da autora), consideramos projeto de letramento

[...] uma prática social em que a escrita é utilizada para atingir algum outro fim, que vai além da mera aprendizagem da escrita (a aprendizagem dos aspectos formais apenas), transformando objetivos circulares como 'escrever para aprender a escrever' e 'ler para aprender a ler' em ler e escrever para compreender e aprender aquilo que for relevante para o desenvolvimento e realização do projeto.

Com esse aporte teórico e com vistas às ações pedagógicas que seriam desenvolvidas na educação básica, foi criado o Subprojeto de Letras-Português "Letras: desenvolvendo projetos de letramento interdisciplinares", aprovado no Edital da Capes $n^{\circ}$. 061/2013. Nessa perspectiva, considerando os letramentos como práticas socioculturais situadas, as escolas são vistas como agências de letramentos por excelência (KLEIMAN, 1995; 2000). No Subprojeto anterior já se iniciou, no último ano, um trabalho voltado ao desenvolvimento de projetos de letramento interdisciplinares, com alunos do nono ano. A primeira experiência foi o projeto "Curta-metragem na sala de aula" ${ }^{2}$, em parceria com o Subprojeto de Ciências, em andamento na mesma escola (FRITZEN et al., 2014).

Como forma de registro da participação dos licenciandos no PIBID, estão (1) a escrita de diários reflexivos, referentes a cada dia de observação ou de intervenção na escola; (2) a produção de diários de leitura ou resenhas de textos teóricos trabalhados nos encontros de formação; (3) a elaboração de relatórios mensais individuais; (4) a publicação de uma síntese mensal das ações de cada escola no blog do PIBID Letras (http://pibidletrasfurb.blogspot.com.br/), bem como

\footnotetext{
${ }^{2}$ Esse projeto interdisciplinar teve como proposta abordar a temática da sustentabilidade socioambiental, a fim de promover entre todos os atores sociais envolvidos na comunidade escolar conscientização e sensibilização em torno da sustentabilidade no âmbito social, ambiental e econômico. Como produto final foram produzidos dez curtas-metragens pelos alunos do nono ano da escola.
} 
(5) a produção e publicação de gêneros discursivos acadêmicos (resumos, trabalhos completos para anais de congressos, relatos de experiência e artigos científicos), como forma de socializar as experiências e resultados das ações desenvolvidas nas escolas, relativas ao Subprojeto Letras. Todas essas formas de registro escrito ocorrem paralelamente à produção coletiva de instrumentos e de materiais didáticos utilizados nas escolas.

Como nossa intenção neste artigo é refletir, a partir das experiências no PIBID, sobre a inserção de licenciandos em práticas de letramentos acadêmicos, o que envolve "falar e atuar em Discursos acadêmicos" (GEE, 1999; ZAVALA, 2010), selecionamos das produções anteriormente mencionadas, os diários de campo reflexivos e os relatórios de três pibidianas, que passaram a integrar o Programa quando iniciaram sua formação no curso de Letras, no primeiro semestre de 2013. Os registros foram, assim, gerados no período de dois anos, relativos a 2013 e 2014. Essas licenciandas passaram a conviver com o espaço escolar já no início de sua formação e tiveram/têm de lidar com as demandas de letramento da Universidade, bem como com as demandas do PIBID.

Se entendermos a formação de professores como um processo que se constitui e se consolida na prática, com a reflexão na e sobre a ação (SCHÖN, 1992), os diários de campo são vistos, neste caso, como importantes instrumentos a fim de provocar a reflexão das licenciandas sobre o cotidiano escolar da educação básica, as ações pedagógicas observadas, enfim a reflexão sobre o vivido, ou, como sugere Winkin (1998, p. 138), "o lugar do corpo-a-corpo consigo mesmos, ante o mundo social estudado". O diário, como um dos instrumentos da etnografia (ERICKSON, 1984; FRITZEN, 2012), foi adotado como registro sistemático dos pibidianos a cada ida à escola e acabou se transformando de fato num lugar privilegiado não só de descrição do visto, mas de discussão, reflexão e avaliação dos licenciandos sobre sua própria participação no PIBID, conforme será focalizado adiante.

Os relatórios mensais individuais servem como sistematização das ações do Subprojeto e de cada escola. A partir dos relatórios é possível para cada bolsista

\footnotetext{
${ }^{3}$ Discursos acadêmicos, com D maiúsculo (cf. GEE, 1999; 2001), referem-se a formas de ser, falar, ouvir, escrever, ler, agir, interagir, acreditar, valorizar, sentir, usar recursos, ferramentas, tecnologias capazes de ativar identidades relevantes no contexto acadêmico (universitário).
} 
participante (licenciandos, supervisores, coordenador) visualizar e acompanhar o desenvolvimento do Subprojeto, repensar o planejamento, avaliar sua participação, elaborar sínteses por escola, projetar ações futuras, entre outros aspectos. Os relatórios foram utilizados aqui como apoio, a fim de contextualizar a participação das licenciandas em diferentes práticas de letramentos relativos à esfera acadêmica. Já os diários são apresentados e discutidos na próxima seção. Para efeitos de análise, consideramos apenas excertos ${ }^{4}$ relacionados aos focos de interesse deste artigo, que incluem práticas de leitura, de escrita e de oralidade na esfera acadêmica, bem como manifestações das escolhas pedagógicas e modos de interação com outros acadêmicos em eventos científicos.

\section{A INSERÇÃO EM PRÁTICAS DE LETRAMENTO ACADÊMICO: ANÁLISES DOS REGISTROS DAS PIBIDIANAS}

Nesta seção, passamos à apresentação e discussão dos registros das três pibidianas, com o objetivo de refletir sobre sua inserção em práticas de letramento acadêmico. Durante o período selecionado para a análise dos dados (2013-2014), as referidas acadêmicas participaram, como apresentadoras e autoras, de eventos locais, regionais e nacionais que poderão ser vistos na apresentação dos excertos de seus diários. A apresentação oral em eventos científicos, a publicação de resumos e trabalhos completos em anais, além de outros gêneros do discurso em periódicos científicos implicam lidar com práticas sociais de leitura e de escrita específicas de um domínio discursivo novo para os/as estudantes, que necessitam "falar e atuar em Discursos acadêmicos" (ZAVALA, 2010, p. 72).

Nem sempre se considera esta passagem entre as práticas de letramento que têm lugar no ensino médio, por exemplo, com os letramentos exigidos no ensino superior. Em geral, espera-se que os estudantes ingressem na Universidade já preparados para lidar com as demandas de letramentos que essa esfera requer (ZAVALA, 2010). Bazerman (2010), ao discutir o processo de produção da linguagem e suas interfaces com aspectos relacionados à originalidade, à imitação e

\footnotetext{
${ }^{4}$ Os excertos foram transcritos tal qual aparecem nos materiais disponibilizados pelos sujeitos da pesquisa. Quando há recortes nesses excertos, utilizou-se a simbologia [...], conforme normas ABNT. Para destacar partes desses excertos, foi utilizado itálico.
} 
ao plágio em tempos de internet, problematiza a educação escolar e sua relação com os letramentos acadêmicos:

\footnotetext{
Muitas salas de aula vivem sob o guarda-chuva de uma única voz de autoridade incorporada em uma aliança entre o livro didático e o professor. [...] Não há necessidade de citação, porque todo mundo sabe que o livro didático define o universo de discurso. Os estudantes que lembram a resposta do livro sem citá-lo são elogiados (BAZERMAN, 2010, p. 171).
}

Em consonância com esses autores, que têm se dedicado a pensar sobre a produção e recepção de textos acadêmicos, também reconhecemos a complexidade envolvida na produção e socialização de conhecimentos nessa esfera, e as relações de poder e de identidade que se tensionam na construção do discurso acadêmico.

Para o desenvolvimento da análise dos registros, organizamos os dados em quatro dimensões, as quais se apresentarão em subseções distintas: (i) por meio de práticas leitoras de conteúdo científico e pedagógico; (ii) por meio de escolhas pedagógicas mais conscientes; (iii) por meio da produção de gêneros discursivos próprios da esfera acadêmica; (iv) por meio da interação com outros em eventos científicos.

É importante destacar que essas quatro dimensões estão inter-relacionadas e não acontecem de modo isolado umas das outras. Unicamente, para fins de apresentação e discussão dos dados, é que serão abordadas de modo separado nas subseções a seguir.

\subsection{PRÁTICAS LEITORAS DE CONTEÚDO CIENTÍFICO E PEDAGÓGICO}

Por meio de diversas práticas leitoras, as estudantes do curso de Letras vão, gradativamente, se inserindo em práticas de letramento acadêmico, que envolvem conteúdos científicos e pedagógicos. Esses conteúdos estão relacionados a enfoques teóricos, conceituais e também didáticos, tais como práticas e projetos de letramento, concepção dialógica da linguagem e gêneros discursivos, os quais dão suporte a escolhas pedagógicas e ao consequente agir docente na educação básica. As leituras ou são orientadas pelas coordenadoras do projeto e debatidas nas formações específicas para esse fim, ou são complementadas e direcionadas pelas próprias alunas, como se depreende pelo depoimento de uma delas: 
(1) "Busca por informações históricas, estruturais e funcionais de cada gênero, além de explicar como nos preparamos através de fundamentação teórica e formações com nossas coordenadoras para o desenvolvimento do projeto na Escola" (Lara, 28.07.2014).

Neste depoimento (1), a estudante Lara indica ter consciência do porquê direciona as leituras, neste caso, para buscar informações históricas, estruturais e funcionais de cada gênero, uma vez que, em 2014, entrou em vigor o projeto "Práticas de letramento envolvendo gêneros da comunicação interpessoal". Assim, explica-se a busca, por exemplo, por informações funcionais acerca dos gêneros selecionados para o trabalho em sala de aula, já que o uso da língua e respectivos sentidos (GEE, 1999) são focos centrais dos encaminhamentos metodológicos do projeto. Além de o sentido das leituras se construir em torno da necessidade de suporte aos encaminhamentos pedagógicos nas escolas, há também outras finalidades que explicam a ocorrência de práticas diversas de leitura, como informam os depoimentos das três professoras em formação, sujeitos desta pesquisa.

(2) "Nesta noite fiz a releitura de alguns textos já lidos por mim na busca de citações para utilizarmos na elaboração de nosso projeto de letramento. Pesquisei nos seguintes livros: "Letramentos múltiplos, escola e inclusão social", de Roxane Rojo, "Letramento um tema de três gêneros", da Magda Soares, "Dicionário de linguagem e linguística", de R. L. Task e no livro "Práticas de letramento no ensino leitura, escrita e discurso", das organizadoras Djane Antocci Correa e Pascoalina Bailon de Oliveira Saleh" (Ana, 14.07.2014).

(3) "Como [...] estamos apenas na parte de preparação, ou seja, lendo diversos artigos relacionados a projetos de letramento, elaborando a escrita do projeto, montando um planejamento das aulas e buscando informações sobre cada gênero tratado [...]" (Lara, 28.07.2014).

(4) "Como acordei inspirada, comecei a escrever [artigo para a revista do PIBID], para isso tive que analisar o edital e os objetivos do subprojeto [Letras: desenvolvendo projetos de letramento interdisciplinares", aprovado no Edital $n^{\circ}$. 061/2013], assim como nosso projeto de letramento [o que se desenvolve na escola de Educação Básica], com isso eu pude refletir que o PIBID é muito importante para dar-nos o gostinho da docência e além disso percebo cada vez mais as contribuições do PIBID para a minha escrita, pois com a escrita de textos em diversos gêneros aumento minha competência comunicativa. Após voltar a ler os documentos citados anteriormente, escrevi 
um pouco e assim que terminei enviei para [aluna Lara] fazer suas contribuições e reflexões" (Amanda, 31.10.2014).

Os três depoimentos das acadêmicas apontam para diferentes práticas de leitura: de artigos de periódicos, de capítulos de livro, de dicionário na área da Linguística, de documentos oficiais do PIBID, como edital e o próprio projeto que direciona os trabalhos no PIBID em Letras. Para além dessas indicações, esses trechos deixam marcas dos papéis que os textos assumem nas interações (cf. BARTON; HAMILTON, 2000) no PIBID, as quais são contextualizadas em objetivos maiores e em práticas sociais desse Programa de iniciação à docência: (i) escrita do projeto de letramento para ser desenvolvido na escola, conforme alunas Ana e Lara indicam em (2) e (3), e (ii) elaboração de artigo a ser publicado em uma revista do PIBID, segundo Amanda, no excerto (4).

As interações com as linguagens especializadas dos textos oportunizam que as acadêmicas construam sentidos com e para as práticas de leitura no contexto acadêmico (FISCHER, 2011; STREET, 2003) do PIBID. Elas revelam motivação, interesse por se inserirem em práticas que envolvem, especificamente, a produção científica, a fim de tornar públicos os trabalhos construídos no PIBID. Esses sentidos também reforçam que as relações de poder e de autoridade não são impositivas às acadêmicas. Em consequência de estarem inseridas em Discursos acadêmicos (GEE, 1999), sentem-se protagonistas de práticas de publicação científica, bem como do projeto de letramento em andamento na escola, o qual exige também conhecimentos científicos.

Assim, as identidades em construção remetem tanto às de pesquisadoras das próprias práticas pedagógicas, quanto às de docentes, que se pautam em uma perspectiva sociocultural dos letramentos, aliada à abordagem etnográfica, as quais oportunizam um movimento constante de ação, reflexão e ação (SCHÖN, 1992). Este dado se manifesta no dizer da aluna Ana:

(5) "Nesta manhã fiz a leitura do artigo A Abordagem Etnográfica na Pesquisa em Linguística Aplicada - Reflexões de uma trajetória ${ }^{5}$, que nos traz uma

\footnotetext{
${ }^{5} \mathrm{O}$ artigo mencionado pela acadêmica, bem como os demais que compõem a obra, foram indicados para leitura pela coordenação do Subprojeto. RODRIGUES, N. C. A Abordagem etnográfica na pesquisa em linguística aplicada - reflexões de uma trajetória. In: FRITZEN, M. P.; LUCENA, M. I. P.
} 
perspectiva diferente de fazer pesquisa, ainda mais de cunho etnográfico, analisando as diferenças que encontramos dentro de uma sala de aula" (Ana, 10.06.2013).

Ainda que o PIBID tenha como objetivo, em primeiro plano, a inserção dos licenciandos em práticas pedagógicas na educação básica e não em práticas de pesquisa científica, fica evidenciada que a abordagem etnográfica (ERICKSON, 1984; FRITZEN, 2012), tão característica em pesquisas em Educação e em Linguística, auxilia, no caso deste projeto do PIBID em Letras, a analisar as "diferenças que encontramos dentro de uma sala de aula" (aluna Ana). Esse dado reforça que o uso das linguagens especializadas e contextualizadas, advindas de artigos lidos no PIBID, ajuda a conduzir relações significativas com o conhecimento pedagógico para o fazer docente.

Essas relações significativas estão marcadas nas formas de as acadêmicas interagirem, de acreditarem e de valorizarem (GEE, 1999, 2001) as práticas no PIBID, como mostradas em meio aos depoimentos já apresentados:

"eu pude refletir que o PIBID é muito importante para dar-nos o gostinho da docência e além disso percebo cada vez mais as contribuições do PIBID para [...] a escrita de textos em diversos gêneros, aumentou minha competência comunicativa (aluna Amanda); a leitura do artigo [...] nos traz uma perspectiva diferente de fazer pesquisa (aluna Ana)".

Em acréscimo, a aluna Lara marca sua posição valorativa (LEA; STREET, 2006) em relação às práticas do PIBID, que envolvem situações diversas de interação, a exemplo das que se dão por meio de leitura de textos:

(6) "O programa nos oferece a oportunidade de participar de eventos e formações acadêmicas que nos permitem trocar experiências com demais bolsistas, supervisores, professores das redes públicas, coordenadores, mestres e doutores nas áreas da educação, o que nos faz ter uma ampla reflexão sobre a elaboração e desenvolvimento de projetos e um aumento significativo de conhecimento através das leituras, conversas e pesquisas" (Lara,12.12.2014).

Como indica Lara, no depoimento (6), há valorização pela troca de experiências com diferentes sujeitos e, em consequência, ocorrem reflexão sobre as

(Orgs.). O olhar da etnografia em contextos educacionais: interpretando práticas de linguagem. Blumenau: Edifurb, 2012. p. 35-54. 
práticas docentes e aumento significativo de conhecimento, confirmando pressupostos do modelo dos letramentos acadêmicos (LEA; STREET, 2006) na constituição letrada acadêmica. Esta posição e a das demais alunas Amanda e Ana, confirmando as propostas direcionadas no PIBID, são coerentes com os objetivos desse Programa, no sentido de aprofundar conhecimentos que oportunizem ao professor em formação estar mais preparado para seu agir docente, de forma que possa reconstruir, em sala de aula, os saberes elaborados com as leituras.

\subsection{ESCOLHAS PEDAGÓGICAS MAIS CONSCIENTES}

A preparação para o agir docente, que dá suporte às escolhas pedagógicas mais conscientes, nas palavras das acadêmicas, deu-se em eventos regionais e nacionais, para além dos estudos com as coordenadoras e as supervisoras do projeto: (i) no IV Enalic e II Seminário Nacional do PIBID, em 2013; (ii) no curso no Laboratório Interdisciplinar de Formação de Educadores (LIFE) da FURB, em 2013; (iii) no Seminário das Licenciaturas, na FURB, em 2013; (iv) na III Jornada Catarinense da Linguagem, em 2014; e (v) na Mostra Integrada de Pesquisa e Extensão (MIPE), na FURB, em 2014.

Temáticas como qualidade na formação docente, tecnologias em sala de aula e identidade do professor foram foco nos diferentes eventos, os quais possibilitaram às acadêmicas reafirmarem suas posições de protagonistas em práticas pedagógicas mais conscientes, direcionadas em escolas da educação básica, com apoio do PIBID.

(7) "O professor precisa saber ensinar efetivamente seus alunos de forma que eles realmente saibam o que estão aprendendo e não apenas mecanizem os exercícios.[...] Ele [o palestrante, professor Libâneo] destacou que o PIBID tem sido um grande diferencial para educação [...]. Definitivamente tenho sentido isso através do PIBID. Sei que será o grande diferencial que terei perante outros profissionais" (Ana, 03.12.2013, a partir do IV Enalic e II Seminário Nacional do PIBID, em 2013).

(8) "António Nóvoa também abordou aspectos importantes sobre a profissão e prática na formação dos professores. [...] O PIBID tem sido um grande diferencial na formação dos novos professores pois faz com que licenciandos aprendam a ensinar de maneira efetiva e lúdica, fazendo com que as aulas se tornem mais atrativas aos alunos. Um aspecto importante que eu tenho 
observado é que há anos [...] se esqueceu de dar importância à qualidade do ensino que se é oferecido. Acredito que o PIBID é um dos programas que veio para solucionar este problema na educação brasileira" (Ana, 05.12.2013, a patir do IV Enalic e II Seminário Nacional do PIBID, em 2013).

(9) "Participamos da mesa redonda "Linguagens tecnologias e atitudes" [...]observei que ela destacou bastante que a língua escrita não é igual a língua falada, e que ainda hoje há muita confusão com o tratamento dessa dicotomia. Foi interessante relembrar isso que vimos no $1^{\circ}$ semestre de nossa graduação. Um ponto importantíssimo que a professora destacou foi que hoje em dia na "era digital" não se pode deixar atrofiar o pensamento crítico do aluno" (Ana,06.12.2013, a patir do IV Enalic e II Seminário Nacional do PIBID, em 2013).

Os dizeres da aluna Ana em (7), (8) e (9) indicam concordância com propostas de não mais realizar unicamente exercícios mecânicos em sala de aula, de valorizar práticas por meio de um ensino mais efetivo e lúdico, com apoio de novas tecnologias, de compreender singularidades na língua falada e escrita, como ela já havia estudado na graduação, e de oportunizar o pensamento crítico dos alunos. Todos esses aspectos representam argumentos recuperados por ela, durante participação em evento nacional, que reforçam como realizar escolhas pedagógicas mais conscientes em favor da educação de qualidade nas escolas. Essa valorização por tais escolhas reforça o reconhecimento de Ana acerca das práticas do PIBID, e consequentemente, de práticas em contextos escolares, como maneiras culturais de utilização do letramento (STREET, 2003), em que estão subjacentes posições teóricas e ideológicas dos participantes.

A aluna Amanda exemplifica uma dessas escolhas conduzidas no projeto do PIBID em Letras da FURB:

(10) "apresentamos um pôster na MIPE sobre nosso projeto atual. [...] As pessoas até ficaram curiosas sobre o uso do telegrama, do fax, então ressaltamos a importância de fazer esse resgate desses gêneros. Também as pessoas ficaram curiosas a respeito do nosso produto final: a revista eletrônica, então explicamos que o projeto está em andamento, mas que assim que finalizarmos iremos publicar no blog do PIBID de Letras da FURB" (Amanda,17.09.2014, a partir de pôster apresentado na MIPE).

O resgate dos gêneros referidos em (10) foi encaminhado a partir de um prévio diagnóstico feito pelas acadêmicas, junto com os alunos, quando do início do referido projeto na escola de educação básica. Isso se justifica pela abordagem 
etnográfica que tem caracterizado as práticas no PIBID de Letras, especialmente pelo enfoque de trabalho baseado em projetos de letramento (KLEIMAN, 2000). Em consequência, o produto proposto, em forma de revista eletrônica, a qual representa uma prática com tecnologias em sala de aula, revelou-se interessante aos ouvintes da comunicação realizada na MIPE/FURB. Esse dado comprova o quanto práticas ditas antigas de comunicação, como fax e telegrama, podem se unir a práticas tecnológicas e valorizadas na atualidade, quando alternativas inovadoras de trabalho são colocadas como foco de reflexão na formação inicial docente.

A formação em curso no LIFE e a apresentação no Seminário das Licenciaturas, ambos na FURB, também foram deflagradores de reflexões (SCHÖN, 1992) sobre o agir docente:

(11) "Discutimos questões como: o desenvolvimento de projeto que utilizam de tecnologia na escola e dificuldades dos professores de se atualizarem com novos métodos de ensino. Apresentamos nosso projeto de curtas [encaminhado no PIBID até 2013] e todos gostaram muito da ideia. Conversamos um pouco sobre como lidar com as novas tecnologias e tivemos a oportunidade de aprender a editar vídeos usando a tecnologia do laboratório" (Lara, 28.09.2013, a partir do curso no LIFE, FURB).

(12) "Eu e a colega [aluna Amanda] apresentamos o nosso projeto e ganhamos muitos elogios, mas também tiveram muitos questionamentos como: Como os alunos lidaram com o fato de apenas três equipes ganharem prêmio; Qual a participação dos pais nos processos de filmagens; Como os alunos conseguiam filmar. Nessa apresentação percebemos mais uma vez como nosso projeto chama a atenção" (Lara, 26.10.2013, a partir de apresentação no Seminário das Licenciaturas, FURB).

Os depoimentos em (11) e (12) indicam resultados significativos da "articulação entre teoria e prática necessárias à formação dos docentes" (CAPES, 2014). Esta articulação é capaz de elevar a qualidade das ações acadêmicas e docentes nos cursos de licenciatura, especialmente por envolver a inserção dos licenciandos em práticas que se caracterizam pelo uso de múltiplas e significativas linguagens aos alunos. Como comprovam as vozes das acadêmicas, editar vídeos, construir o projeto de curta-metragem na escola com os alunos e inserir os pais desses alunos nos processos de filmagens são caminhos pedagógicos possíveis, inovadores, mais situados (LANKSHEAR; GEE; KNOBEL, 2002) com desafios da sociedade 
tecnológica atual e que despertam questionamentos e muito interesse nos demais interlocutores.

\subsection{PRÁTICAS DE ESCRITA ${ }^{6}$ DE GÊNEROS DISCURSIVOS DA ESFERA ACADÊMICA}

Passamos a discutir neste espaço, a forma de inserção das licenciandas em práticas de letramento acadêmico por meio da escrita de gêneros discursivos próprios dessa esfera e elaboração de apresentações orais para congressos. Essa dimensão esteve bastante presente nos diários das acadêmicas, uma vez que elas passaram a atuar como autoras na esfera acadêmica já no primeiro ano da formação inicial e primeiro ano no PIBID, em 2013.

Os excertos abaixo sinalizam os primeiros movimentos de escrita de um trabalho a ser submetido a um congresso nacional, no primeiro ano de participação das licenciandas no PIBID.

(13) "Após voltar do minicurso do $\mathrm{Nel}^{7}$ eu comecei a fazer minha parte do resumo que será enviado para o Enalic. Tínhamos que responder a cinco perguntas no resumo e eu fiquei com as duas primeiras [...] Então para elaborar o resumo eu pesquisei nos arquivos sobre o projeto no Ava para encontrar os objetivos do projeto, e começar o resumo. Assim que terminei mandei para as meninas para elas verem e continuarem a parte delas" (Amanda, 14.09.2013).

(14) "Eu, Amanda e Lara, trabalhamos na elaboração do resumo que vamos submeter ao Enalic, que será realizado em Uberaba, Minas Gerais em dezembro. A elaboração se deu por conta de cada uma construindo um texto sobre o nosso Subprojeto. Trocamos e-mails com as Coordenadoras [cita os nomes] também" (Ana, 15.09.2013).

É possível constatar as estratégias que as licenciandas foram utilizando para construir o texto, que deveria ser de autoria das três, sobre a experiência que estavam desenvolvendo em uma das escolas parceiras do Programa. A escrita envolveu voltar a outras leituras como o próprio Subprojeto Letras-Português

\footnotetext{
${ }^{6}$ Houve vários registros de práticas de oralidade ou que se situam na interface oralidade/escrita, mas que não foram consideradas na análise pelas limitações de espaço neste artigo.

${ }^{7} \mathrm{O}$ NEL - Núcleo de Estudos Linguísticos, programa de extensão da FURB, tem sido um parceiro nas formações do PIBID.
} 
(arquivos sobre o projeto), disponível no ambiente virtual de aprendizagem (AVA $)^{8}$ e a responder a perguntas que elas levantaram para melhor orientar a escrita. Inicialmente foi um trabalho individual de escrita, em que cada uma ficou encarregada de uma parte. Depois o trabalho conjunto, em diálogo com as coordenadoras do Subprojeto, como mencionado no excerto (14).

(15) "Releitura, readequação e elaboração do resumo que submeteremos ao Enalic em dezembro. Sempre nos organizamos da seguinte maneira: Amanda começa o resumo, eu continuo e acrescento algumas ideias interessantes e Lara faz o fechamento. Trabalhamos bem assim! E acabamos nos acostumando a trabalhar desse jeito (-)" (Ana, 29.09.2013).

Nesse processo de escrita do texto acadêmico, as licenciandas vão criando um modo de lidar com as tarefas de produção, buscando estratégias para darem conta, apropriarem-se da escrita acadêmica. No primeiro ano do PIBID, acostumaram-se a trabalhar dividindo a construção escrita do texto, neste caso o resumo, em etapas, em que cada uma seria responsável por uma delas. Verifica-se que há a compreensão de que a escrita, a produção de um texto, o qual circulará para além do âmbito da sala de aula ou do Programa, não se dá como um produto acabado, mas envolve releitura, o debruçar-se sobre o texto como leitor, e readequação, a intervenção na escrita revendo as formas de dizer no discurso acadêmico.

(16) "Nesta noite fiz a leitura e modificação dos seguintes textos: texto para o blog do PIBID, resumo para o Enalic 2014 e o Projeto de Letramento que estamos elaborando. Todos os textos foram encaminhados a todas por email, exceto o texto para o blog que foi apenas para a [cita a coordenadora] e para o NEL" (Ana, 27.07.2014).

(17) "Nesta manhã fiz a releitura do projeto de letramento que estamos desenvolvendo e fiz as alterações que eram sugeridas pela [cita a coordenadora]. Após mandei por e-mail para todas darem mais uma olhada" (Ana, 20.10.2014).

Nos excertos acima, mais uma vez, constata-se que o trabalho com a reescrita se tornou uma constante nas rotinas do Programa. As licenciandas relatam

\footnotetext{
${ }^{8}$ O AVA é um recurso bastante usado no Subprojeto Letras-Português. Nesse ambiente são feitas postagens de material teórico como artigos científicos, relatórios individuais, trabalhos desenvolvidos em cada escola parceira, desde instrumentos utilizados como diagnóstico e sua análise, bem como propostas de trabalho e os projetos de letramento desenvolvidos.
} 
essa atividade como um procedimento inerente à produção dos gêneros do discurso acadêmico, que inclui postagens no blog do Subprojeto, resumo para evento e o projeto de letramento em desenvolvimento na escola. Como todos esses textos teriam leitores/interlocutores reais, membros dos Discursos acadêmicos, era importante essa troca entre todos os bolsistas, num trabalho coletivo de construção da escrita, que envolve formas de ser, de agir, valorar, entre outras, que vão além do uso das convenções de escrita (GEE, 1999; 2001).

(18) "Como eu e minhas colegas temos interesse de participar da Jornada da Linguagem, nessa noite, comecei a escrever a primeira versão do resumo para a Jornada da Linguagem, como podem ser apenas três autores, o meu grupo da Machado resolveu então escrever dois resumos para que todas possam participar do evento com uma publicação. É muito importante todo aprendizado que o PIBID nos proporciona além das oportunidades de participação em eventos, isso é muito valioso" (Amanda, 07.04.2014).

(19) "Após conversar com minhas colegas, resolvemos escrever resumos para a MIPE e para o Enalic, como eu prefiro começar a escrever, iniciei a escrita dos resumos para isso recorri aos objetivos do nosso projeto e também na sequencia didática. Esses resumos foram mais difíceis para serem começados pois o projeto está em andamento, mas nada é impossível, logo que escrevi um pouco enviei para Ana e para Lara o do Enalic e o da Mipe enviei na segunda-feira dia 28 para Ana, Lara, Ana e [cita a supervisora]" (Amanda, 30.07.2014).

Conforme mencionado anteriormente, desde o primeiro ano de inserção no PIBID, as licenciandas participaram de eventos científicos locais e nacionais. Isso Ihes deu autonomia para tomarem decisões entre elas para participarem de outros eventos e para criarem condições para que todo o grupo participasse com uma publicação. Nos excertos (18) e (19), novamente se observa o processo coletivo de escrita entre as bolsistas e a professora supervisora. As licenciandas parecem compreender que o espaço da academia é um locus de socialização de experiências e conhecimentos, mesmo em face de um trabalho não concluído, mas sobre o qual já teriam algo a dizer. Há ainda uma expressão valorativa de Ana sobre sua inserção no Programa (isso é muito valioso), que revela a formação de uma professora que reflete sobre suas maneiras de estar, de agir e interagir nesse contexto acadêmico.

(20) "O projeto curtas do ano passado sem dúvidas foi um sucesso. Nossa coordenadora nos incentivou muito a relatar nossa experiência em forma de 
artigo para tentarmos publicar na revista da Olh@res. Esse incentivo valeu muito, pois vou para o terceiro semestre, nunca escrevi artigo e achei muito fraca a disciplina de produção de texto. O [cita o nome de um colega pibidiano] que já é bem experiente e já está quase se formando nos (eu, Amanda e Ana)deu uma luz e está nos auxiliando. O mais difícil está sendo referenciar todas as práticas. Tivemos muitas formações e leituras de diversos textos referentes a projetos de letramento e sobre como elaborar curtas, mas eu achava que isso era para ajudar no desenvolvimento do projeto, mas agora vejo que ajuda (e muito) a explicar o porquê agimos de certa forma, além de explicar da onde vem as ideias e por que o projeto deu tão certo" (Lara, 20.01.2014).

Nesse excerto, a licencianda Lara utiliza a escrita do diário como uma forma de não apenas relatar as tarefas cumpridas e a cumprir, mas de refletir sobre as ações do Subprojeto e sobre sua inserção em práticas de letramento acadêmico. Como membro ainda não totalmente inserido -outsider (GEE, 2001) -na prática de escrita do artigo, ela se sentia insegura para produzir tal gênero e reconhece que o incentivo da coordenação do Subprojeto e a parceria com um colega mais experiente foram essenciais nessa construção do texto. Há ainda uma crítica da licencianda relativa a uma disciplina ${ }^{9}$ que deveria estar voltada à produção e recepção de textos acadêmicos, mas que, segundo ela, não teria suprido essa necessidade.

É preciso considerar que uma ou duas disciplinas no currículo não garantirão automaticamente a inserção dos licenciando sem práticas de letramento exigidas nessa esfera. Conforme já salientamos neste artigo, há uma complexidade de fatores relacionados aos Discursos produzidos no âmbito acadêmico, que vão além de convenções linguísticas, mas que se relacionam a dimensões mais amplas como as formas próprias de produção de conhecimentos nesse campo, as relações de poder que se configuram nele, bem como a própria projeção de identidades (vide, entre outros, CANAGARAJAH, 2002; ZAVALA, 2010). Ao produzir um texto acadêmico como um artigo, Lara reflete sobre o próprio sentido das leituras teóricas, sobre a relação que os aportes teóricos estudados nas formações do Subprojeto têm

\footnotetext{
${ }^{9}$ As disciplinas Produção de Texto I e II fazem parte das disciplinas do Eixo das Licenciaturas desde 2004 e são ministradas nos dois primeiros semestres desses cursos. O objetivo geral da disciplina de Produção de Texto I é "Aprimorar a leitura e produção escrita de textos da esfera acadêmica. Habilitar o acadêmico a reconhecer características essenciais do resumo e da resenha, bem como produzir estes gêneros textuais.". De Produção de Texto II é "Aprimorar a leitura e produção escrita de textos da esfera acadêmica. Habilitar o acadêmico a reconhecer características essenciais do ensaio/paper, artigo e relatório, bem como produzir estes gêneros textuais."
} 
para ela ao relatar e analisar as ações pedagógicas do grupo, as escolhas feitas, o pensar sobre o feito e o vivido.

(21) "Nesta noite fiz a releitura de alguns textos já lidos por mim na busca de citações para utilizarmos na elaboração de nosso projeto de letramento. Pesquisei nos seguintes livros: "Letramentos múltiplos, escola e inclusão social", de Roxane Rojo, "Letramento um tema de três gêneros" da Magda Soares, "Dicionário de linguagem e linguística" de R. L. Task e no livro "Práticas de letramento no ensino leitura, escrita e discurso" das organizadoras Djane Antocci Correa e Pascoalina Bailon de Oliveira Saleh" (Ana, 14.07.2014).

Nesse excerto (21) do diário, como já o dispomos na seção 4.1, poderíamos considerar que essa busca de citações seria apenas um gesto de acrescentar trechos teóricos ao gênero do discurso que Ana e o grupo estavam produzindo. No entanto, esse gesto é revelador de uma compreensão do texto acadêmico como constituído de muitas vozes que precisam ser orquestra das: a voz do autor (das autoras) e as vozes das autoridades, dos teóricos do campo da linguagem, referências na área. Conforme Zavala, baseada em Boughey (2000, apud ZAVALA, 2010, p. 76), “[...] produzir um texto acadêmico é como cantar uma música com um coro atrás. A necessidade de ter essas vozes para cantar em harmonia ou em oposição a elas é uma espécie de regra sobre a forma na qual se constrói o conhecimento acadêmico".

(22) "Durante a escrita do artigo reparamos que, como dizem nossos aportes teóricos, todo projeto deve ter a resolução de um problema e através disso desenvolver estratégias para resolvê-lo, porém nosso projeto não teve esse fundamento e acho que isso fez falta, pois o principal objetivo não é dinamizar as aulas e sim inserir os conhecimentos necessários para o letramento através de projetos, como aconteceu no curtas que envolveu diversas questões ambientais e no produto final além de mostrar o avanço na escrita(através da narrativa) e desenvolvimento da comunicação (através das filmagens), mostrou como lidar com essas questões" (Lara, 21.10.2014).

No excerto (22), a acadêmica Lara, já no segundo ano do curso e de sua participação no PIBID, faz uma autorreflexão sobre o trabalho desenvolvido na educação básica. É no momento de escrita do artigo, de voltar aos aportes teóricos e redigir o texto a fim de socializar as experiências vividas nas duas escolas em que ela e seu grupo atuaram, que ela registra no diário sua reflexão sobre as ações do 
Subprojeto. Nesse movimento entre a prática, as leituras teóricas e a escrita do texto acadêmico, a licencianda é capaz de fazer uma crítica à própria ação pedagógica do grupo, ao compreender princípios básicos de um projeto de letramento: o papel central do aluno, como "sujeito de conhecimento" num "ensino orientado para a resolução de problemas" (OLIVEIRA; TINOCO; SANTOS, 2011, p. 45).

(23) "Essas experiências que o PIBID têm proporcionado, como essa de produzir um artigo para a publicação em um evento, tem me feito aprender muito e tem me ajudado a me constituir como futura pesquisadora, deixando o sonho de fazer o mestrado, cada vez mais perto de se tornar realidade!" (Ana, 27.10.2014).

As palavras de Ana no seu diário sinalizam para a formação de uma professora pesquisadora. A inserção em práticas de letramento por meio da sua participação no PIBID, como autora que se prepara para apresentar seu trabalho num evento, amplia sua visão da própria esfera e lhe faz entrever outras possibilidades como continuidade de sua formação inicial.

Todas essas produções escritas relatadas nos diários das acadêmicas, além de outras que não foram aqui mencionadas, são reveladoras de um processo de inserirem-se, como membros autênticos, em práticas de letramentos acadêmicos, por meio de diálogos e interações com os demais pibidianos, de reflexões teóricas, das práticas pedagógicas e de um movimento de autorreflexão constante.

\subsection{INTERAÇÃO COM OUTROS ACADÊMICOS EM EVENTOS CIENTÍFICOS}

Nesta seção, passamos a discutir os registros dos diários que se relacionam com a interação que as acadêmicas tiveram com outros licenciandos e professores/pesquisadores em eventos científicos. O tornar-se membro do Discurso acadêmico também requer a socialização dos conhecimentos construídos, das ações e práticas efetivadas para os demais membros da esfera.

(24) "Eu e Amanda apresentamos o nosso projeto e ganhamos muitos elogios, mas também tiveram muitos questionamentos como: como os alunos lidaram com o fato de apenas três equipes ganharem prêmio?; qual a participação dos pais nos processos de filmagens?; como os alunos conseguiam filmar?" (Lara, 26.10.2013). 
No excerto (24), como já o trouxemos em (12), há o registro que Lara faz em seu diário sobre a participação dela e de Amanda num evento ocorrido na própria Universidade, o seminário anual, que agrega estudantes de diferentes cursos de licenciatura. Ao socializar suas experiências e ações do PIBID relativas aos alunos da educação básica, ela escreve sobre elogios, mas também questionamentos. A interação com outros licenciandos, com professores das escolas do município e docentes da Universidade mostrou a ela outras facetas do trabalho que talvez ela e o grupo não tenham percebido. A participação no evento como autora/apresentadora mostra a ela que esse papel é assumido com todas as suas responsabilidades e desdobramentos. O ter a dizer num evento como esse, envolve também o saber ouvir críticas do outro e se posicionar em relação a elas. Certamente as perguntas dos demais participantes que ela registrou no diário devem levá-la a refletir sobre as próprias ações pedagógicas do subprojeto e a repensar ações futuras.

Os excertos a seguir (25) e (26) dizem respeito aos registros sobre a participação das acadêmicas no Enalic, ocorrido na Universidade Federal do Triângulo Mineiro, em dezembro de 2013.

(25) "À noite nos dirigimos até a sala onde eu, Lara e Amanda fomos apresentar nosso trabalho desenvolvido no decorrer deste ano. Conhecemos trabalhos que envolviam a leitura com crianças do ensino fundamental das séries iniciais. [...]Enfim chegou a hora de nos apresentarmos, apesar do nervosismo fomos muito bem. Apresentamos o trabalho desenvolvido por nós aos participantes da comunicação oral de nossa sala fomos muito questionadas no sentido de como nós desenvolvemos o projeto. Se mostraram muito interessados e bastante curiosos para verem os curtasmetragens produzidos pelos alunos. Lá encontramos uma acadêmica da $7^{a}$ fase de Letras da Universidade Estadual de Goiás e também uma professora Universitária que trabalha como Coordenadora do PIBID da mesma instituição. Elas nos questionaram quanto às ações produzidas em nosso projeto de letramento e também sobre nossas ações no PIBID. Falamos que antes de começarmos a trabalhar com nossos alunos, participamos de diversas formações que nos auxiliaram nas análises das produções dos alunos como também com o uso das diversas ferramentas e práticas que pudemos aplicar com nossos alunos. Foi uma conversa muito interessante, pois pudemos conhecer um pouco sobre a Universidade delas assim como elas conheceram um pouquinho sobre a nossa" (Ana, 04.12.2013).

(26) "À noite apresentamos o nosso projeto em meio a uma sala com uma grande diversidade de temas, mas todos estavam ligados aos letramentos. Pessoas de diversos lugares se interessaram, e muito, pelo nosso trabalho 
sendo assim, surgiram vários questionamentos como: se vamos publicar, onde as pessoas podem ver os curtas-metragens elaborados pelos alunos, entre outros. Em nossa apresentação garantimos que o nosso projeto deu muito certo, que o PIBID fez muita diferença em nossa caminhada discente e quando comentamos que estávamos apenas no segundo semestre do curso de Letras, o grupo que estava na sala ficou chocado, pois perceberam que a bagagem de conhecimento, aprendizado e experiência que adquirimos esse ano foi gigantesca. Enfim fomos muito elogiadas e a maioria das perguntas na hora do debate vieram para nós" (Lara, 04.12.2013).

Ana e Lara, após um ano no curso de Letras e no PIBID, pela primeira vez num congresso nacional, relatam em seus diários as experiências que tiveram com a socialização das práticas desenvolvidas no Subprojeto Letras-Português. Em ambos os excertos, é possível constatar que a apresentação da comunicação gerou muitas "atitudes responsivas ativas", no dizer de Bakhtin (1997, p. 290), por parte dos interlocutores. Considerando a esfera acadêmica como um locus de debate e de produção de conhecimentos, seria natural que houvesse nesse evento de letramento atitudes de concordância, de discordância, questionamentos, que instigaram as acadêmicas a se posicionarem diante de seus ouvintes/interlocutores a respeito de suas escolhas teóricas e sua relação com as ações do Subprojeto. Ainda nas palavras de Bakhtin (1997, p. 291), "cedo ou tarde, o que foi ouvido e compreendido de modo ativo encontrará um eco no discurso ou no comportamento subsequente do ouvinte". A interação com seus pares, com ouvintes mais experientes, como a professora universitária coordenadora de outro subprojeto, promoveu uma interlocução bastante positiva, conforme relato de Ana no seu diário (26).

(27) "No dia 12 foi a minha vez de me apresentar. Bateu um nervosismo, mas isso é normal. [...] Fiz um breve relato sobre nosso subprojeto, sobre o que desenvolvemos nesse ano e fechei com a produção de um dos alunos. Me fizeram bastante questionamentos sobre o conceito de projetos de letramento e também sobre as diversas etapas. Tive a sorte de pegar uma comunicação oral com bastante gente e também com 3 professoras doutoras. Isso ajudou na hora do debate enriquecendo-o" (Ana,12.12.2014, referente ao Enalic).

Um ano depois da apresentação no Enalic em Uberaba, Ana volta a apresentar o trabalho desenvolvido no subprojeto do PIBID neste mesmo evento nacional importante da área, que aconteceu na Universidade Federal do Rio Grande do Norte, em Natal. Desta vez, no segundo ano do curso e do PIBID, ela está 
sozinha diante dos ouvintes. Embora ela registre o nervosismo ao assumir a palavra diante do grupo, ela já parece demonstrar saber lidar com essa situação. Na interação com os demais participantes, a acadêmica novamente relata a interlocução com os ouvintes, seus questionamentos com relação à teoria e ao próprio desenvolvimento do projeto. Ela sinaliza uma atitude valorativa positiva diante do fato de ter tido a sorte de falar para uma sala com várias pessoas e com pares mais experientes, como as professoras doutoras. Esse gesto desvela o reconhecimento de Ana sobre a importância de ouvir a voz do outro, de interagir com diferentes atores sociais num evento acadêmico.

(28) "Nessa tarde, tive a apresentação do pôster que eu, Lara e [cita a coordenadora] fizemos para Jornada. Cheguei meia hora antes da apresentação para colocar o pôster e enquanto não começava a apresentação fiquei junto com a Ana. Quando eram 17h eu fui apresentar o trabalho, todas as pessoas a quem foi apresentado o projeto gostaram muito, acharam uma prática inovadora, inclusive as pessoas da organização do evento elogiaram muito o trabalho feito na escola. [...] Teve um diretor de uma escola que também adorou e falou que vai tentar fazer algo parecido em sua escola. Isso me deixa muito feliz ver como as pessoas de fora do nosso contexto gostaram do projeto. Os elogios sempre são ótimos e sempre dão vontade, incentivo de continuar desenvolvendo práticas assim: inovadoras. Foi muito bacana mesmo" (Amanda, 23.05.2014, a partir da participação na Jornada Catarinense da Linguagem).

Amanda relata no seu diário a experiência com a socialização do projeto desenvolvido no ano anterior, que envolveu a produção de curtas-metragens sobre o tema sustentabilidade. Os registros da acadêmica sinalizam os efeitos positivos da interlocução com os pares, com as organizadoras do evento e com um diretor de uma escola. Nem sempre os eventos científicos promovem a integração entre Universidade e escola, mas essa integração, nesse caso, faz parte dos objetivos do evento $^{10}$. Assim, Amanda teve a oportunidade de dialogar com um gestor de uma escola e receber um feedback positivo a respeito do trabalho efetivado na escola parceira do PIBID. A licencianda usa duas vezes a expressão "prática(s) inovadora(s)". No âmbito do PIBID, nos documentos oficiais ${ }^{11}$ e nos discursos dos

\footnotetext{
${ }^{10}$ Os Anais da Jornada podem ser acessados no link: http://www.jornadadelinguagem.faed.udesc.br/. Acesso em: 24 mar. 2015.

${ }^{11}$ Um dos objetivos do Programa, de acordo com a Capes, é: "inserir os licenciandos no cotidiano de escolas da rede pública de educação, proporcionando-lhes oportunidades de criação e participação
} 
Subprojetos na instituição, essa expressão, juntamente com a necessidade de um trabalho interdisciplinar, circula com bastante frequência e vem sendo revozeada. Certamente há diferentes sentidos que se constroem sobre o que significaria uma prática docente inovadora e interdisciplinar. Por esse motivo, a fim de não serem tratados como dados e naturalizados, há necessidade de se discutir e problematizar esses conceitos $^{12}$. Essa foi, inclusive, uma demanda levantada recentemente em uma reunião institucional do PIBID e que será foco de um encontro específico.

(29) "Todos os questionamentos que já foram feitos em outros eventos, mostraram que devemos escrever sempre mais, relatando cada detalhe, inclusive as adversidades que aconteceram na convivência com os alunos, as dúvidas e avanços deles, para ficar claro que em um projeto pode acontecer de tudo. Esse artigo proporciona mais uma vez a valiosa oportunidade de melhoramento da escrita, pois só ampliamos nossa competência de relatar adequadamente, escrevendo" (Lara, 25.07.2014).

Nesse excerto, ao escrever um artigo para o Colóquio Nacional ${ }^{13}$, Lara faz uma reflexão sobre a própria produção dos gêneros do discurso que têm servido para socializar as ações do Subprojeto. A partir das interações que teve com outros membros da esfera acadêmica em eventos científicos, ela compreende que a escrita envolve a descrição detalhada das práticas desenvolvidas na escola, mas também a discussão do não previsto, das adversidades, das inquietações e dúvidas que surgiram durante o processo. As anotações de Lara em seu diário sinalizam que suas experiências a partir do trabalho com projetos de letramento mostrou que há vários desafios a serem superados quando se pretende romper com a lógica da fragmentação do ensino por conteúdos. Sugerem ainda uma autorreflexão como escritora/autora, como alguém que tem o que dizer, tem razões para dizer o que quer dizer, tem para quem dizer e cada vez mais se apropria das estratégias do como dizer (cf. GERALDI, 1991) para atuar no Discurso acadêmico.

em experiências metodológicas, tecnológicas e práticas docentes de caráter inovador e interdisciplinar que busquem a superação de problemas identificados no processo de ensinoaprendizagem." Disponível em: <http://www.capes.gov.br/educacao-basica/capesPIBID>. Acesso em: 24 mar. 2015.

${ }^{12}$ Não será realizada uma discussão, neste artigo, acerca desses conceitos, por questão de delimitação do assunto. Porém, discussões, em reuniões do PIBID, na FURB, esta já foi encaminhada com tal finalidade.

${ }^{13} \mathrm{O}$ artigo está disponível nos Anais do II Colóquio Nacional Diálogos entre linguagem e educação, IX Encontro do NEL e II Seminário do PIBID Letras da FURB: Disponível em: <http://www.tecnoevento.com.br/nel2014/anais/artigos/art26_2.pdf>. Acesso em: 24 mar. 2015. 


\section{CONSIDERAÇÕES FINAIS}

Ao percorrermos os diários dessas três licenciandas, encontramos o registro de práticas pedagógicas desenvolvidas no Subprojeto de Letras no âmbito do PIBID, que incluem as ações do Subprojeto, mas também várias outras dimensões da participação dessas professoras em formação no Programa. Os resultados da análise de sua inserção em práticas de letramento acadêmico sinalizam como as licenciandas vão constituindo sua nova identidade - a docente, ao lado da identidade de insiders, como membros autênticos, que se mostram, falam e atuam em Discursos acadêmicos (ZAVALA, 2010).

Ao interagirem com leituras tanto de conteúdo pedagógico como leituras teóricas do campo da linguagem, ao produzirem gêneros acadêmicos, ao se tornarem autoras por meio de publicações diversas, ao socializarem suas experiências em eventos, as licenciandas estão num processo contínuo de construção de sentidos situados nas práticas. Essa diversidade de práticas de leitura e de escrita oportunizadas pelo PIBID se inter-relaciona e vai constituindo a trajetória de letramento dessas futuras professoras.

Essas diferentes formas de inserção em práticas sociais de letramento acadêmico marcam fronteiras entre o ser estudante, no Ensino Superior, e o ser professor (FISCHER, 2011) na educação básica, as quais se constroem com apoio de interações entre pibidianos, entre estes, coordenadoras e supervisoras do projeto e, de modo muito nítido, entre conteúdos de ordem científica e pedagógica que são discutidos, refletidos nas ações do PIBID constantemente.

A motivação, o interesse e a responsabilidade por estarem inseridas nesse Programa de iniciação à docência fazem das acadêmicas - sujeitos das análises neste artigo - protagonistas de decisões e não apenas receptoras e reprodutoras de conhecimentos, o que comprova o encaminhamento de escolhas pedagógicas mais conscientes para a educação básica. Em acréscimo, a perspectiva etnográfica, por parte da coordenação do Subprojeto, para orientar os trabalhos com práticas efetivas de letramento, também reforça os resultados alcançados nesse projeto do PIBID, o qual posiciona essas acadêmicas de modo ativo nessas práticas. 


\section{MARISTELA PEREIRA FRITZEN}

Doutora em Linguística Aplicada pela UNICAMP, com período sanduíche (20062007) na Universidade de Freiburg. Alemanha. Professora do Departamento de Letras e do Programa de Mestrado em Educação da Universidade Regional de Blumenau (FURB). Coordenadora do Subprojeto Letras-Português do PIBID-FURB.

\section{ADRIANA FISCHER}

Doutora em Linguística pela Universidade Federal de Santa Catarina (UFSC), com período sanduíche (2006) na Universidade do Minho, Braga, Portugal. Professora do Departamento de Letras e do Programa de Pós-Graduação/Mestrado em Educação da Universidade Regional de Blumenau (FURB).

\section{REFERÊNCIAS}

BAKHTIN, M. M. Estética da criação verbal. 2. ed. São Paulo: Martins Fontes, 1997. $512 \mathrm{p}$.

BARTON, D.; HAMILTON, M. Literacy practices. In: BARTON, D.; HAMILTON, M.; IVANIC, R.Situated literacies: reading and writing in context. London/ New York: Routledge, 2000. p. 7-15.

BAZERMAN, C. Pagando o aluguel: particularidade e inovação no processo de produção da linguagem. In: VÓVIO, C.; SITO, L.; GRANDE, P. (Orgs.) Letramentos: rupturas, deslocamentos e repercussões de pesquisas em linguística aplicada. Campinas, SP: Mercado de Letras, 2010. p.163-175.

CANAGARAJAH, S. A geopolitics of academic writing. Petesburgo: Editora Universidade de Petesburgo, 2002. $320 \mathrm{p}$.

CAPES. PIBID - Programa Institucional de Bolsa de Iniciação à Docência, 2014. Disponível em: <http://www.capes.gov.br/educacao-basica/capesPIBID>. Acesso em: 28 jan. 2015.

DIONíSIO, M. L. Educação e literacias. Relatório para professor associado do grupo disciplinar de Metodologias da Educação, do Instituto de Educação e Psicologia da Universidade do Minho. Braga, Portugal, 2006. 121 p.

ERICKSON, F. What makes school ethnography 'ehtnographic'? Antropology and Education Quarterly, v. 15, n. 1, p. 51-66, Spring, 1984.

FISCHER, A. Ser professor na Educação Básica: letramentos em construção em um Curso de Letras. Roteiro, Joaçaba, v. 36, n. 2, p. 267-292, jul./dez. 2011.

FISCHER, A. A construção de letramentos na esfera acadêmica. 2007. 340 p. Tese (Doutorado em Linguística)-Universidade Federal de Santa Catarina, Florianópolis. 
FRITZEN, M. P. O olhar da etnografia no fazer pesquisa qualitativa: algumas reflexões teórico-metodológicas. In: FRITZEN, M. P.; LUCENA, M. I. P. (orgs.). O olhar da etnografia em contextos educacionais: interpretando práticas de linguagem. Blumenau: Edifurb, 2012. p. 55-72.

FRITZEN, M. P. et al. Curta-metragem e sustentabilidade: multiletramentos no subprojeto Letras-Português do PIBID. Olh@res, Guarulhos, v. 2, n.2, p. 352-374, dez. 2014.

GEE, J. P. Reading as situated language: a sociocognitive perspective. Journal of adolescent \& adult literacy, v.8, n. 44, p. 714-725, 2001.

GEE, J.P. Social linguistics and literacies.Ideology in Discourses. 2.ed. London/Philadelphia: The Farmer Press, 1999.

GERALDI, J. W. Portos de passagem. São Paulo: Martins Fontes, 1991.

HEATH, S. B. Ways with words, language, life and work in communities and classrooms. New York: Cambridge University Press, 1983.

HUBER, R. et al. Construindo narrativas na escola Carlos Maffezzolli. In: CERVI, G. M. et al. (Orgs.). Formação docente: qualificando conceitos em diferentes tempos e espaços. Blumenau: Edifurb, 2013, p. 53-60.

KLEIMAN, A. B.(Org.). O processo de aculturação pela escrita: ensino da forma ou aprendizagem da função? In: KLEIMAN, A. B.; SIGNORINI, I.(orgs.) O ensino e a formação do professor: alfabetização de jovens e adultos. Porto Alegre: ARTMED, 2000. p. 223-243.

KLEIMAN, A. B. Os significados do letramento. Campinas, S.P: Mercado de Letras, 1995.

KLOTH, G.; SCHLICHTING, T. de S. Mídias digitais em atividades do PIBID: experiências com os anos finais do ensino fundamental. Revista Práticas de Linguagem, v. 4, n. 2, p. 58-64, jul./dez. 2014.

LANKSHEAR, C., GEE, J. P.; KNOBEL, M. Introduction. In: literacies. Philadelphia: Open University Press, 2002. p. 1-7. . Changing

LEA, M. R.; STREET, B. V. The academic literacies model: theory and applications. Theory into Practice, v. 45, n. 4, p. 368-377, Fall, 2006.

OLIVEIRA, M. S.; TINOCO, G. M. A. de M.; SANTOS, I. B. A. Projetos de letramento e formação de professores de língua materna. Natal: EDUFRN, 2011.

SCLIAR-CABRAL, L.; GRIMM-CABRAL, L. Caracterização das qualidades narrativas em pré-escolares. Ilha do Desterro: a bilingual journal of language and literature.

Florianópolis, v.11, p. 56-74, 1984. 
SCHÖN, D. A. Formar professores como profissionais reflexivos. In: NÓVOA, A. (Org.) Os professores e a sua formação. 3. ed. Lisboa: Dom Quixote, 1992. p. 77-91.

STREET M. B. V. Abordagens alternativas ao letramento e desenvolvimento. Paper entregue após a Teleconferência Unesco Brasil sobre Letramento e Diversidade, out. 2003. Disponível em:<http://telecongresso.sesi.org.br/templates/header/index.php? language $=$ pt\&modo=biblioteca\&act=categoria\&cdcategoria=22>. Acesso em: 10 nov . 2003.

THE NEW LONDON GROUP. A pedagogy of multiliteracies. Design of social futures. In: COPE, B.; KALANTZIS (Eds.). Multiliteracies. Literacy learning and design of social futures. London/New York: Routledge, 2000. p. 9-37.

WINKIN, Y. A nova comunicação: da teoria ao trabalho de campo. Trad. Roberto Leal Ferrreira. Campinas, SP: Papirus, 1998.

ZAVALA, V. Quem está dizendo isso?: letramento acadêmico, identidade e poder na educação superior. In: VÓVIO, C.; SITO, L.; GRANDE, P. (Orgs.) Letramentos: rupturas, deslocamentos e repercussões de pesquisas em linguística aplicada. Campinas, SP: Mercado de Letras, 2010. p. 71-95. 